\title{
Protective roles of plant proteins in conferring tolerance to heat stress
}

\section{Omid Askari-Khorasgani ${ }^{1}$, Mohammad Pessarakli ${ }^{2 *}$}

\author{
${ }^{l}$ Young Researchers and Elite Club, Department of Horticultural Sciences, College of \\ Agriculture \& Natural Resources, Isfahan (Khorasgan) Branch, Islamic Azad University, \\ Iran \\ ${ }^{2}$ Professor, School of Plant Sciences, College of Agriculture and Life Sciences, The \\ University of Arizona, Tucson, AZ 85721, USA \\ *Corresponding Author E-mail: Mohammad Pessarakli pessarak@email.arizona.edu
}

\begin{abstract}
Intensified by global warming, heat stress is one of the major concerns in many farmlands that severely disturbs plant productivity. Plant genetic engineering by regulating heat shock proteins (HSPS), RNA-binding proteins (RBPS), and molecular chaperones is an efficient strategy for maintaining plant productivity under heat stress conditions. Plant performance and tolerance to heat stress are highly dependent on their balance, interactions, structural and functional diversities. Thus, this review article is undertaken to discuss the effectiveness of these proteins in conferring tolerance to heat stress and to incentivize their coregulation to achieve better results in breeding programs in future.
\end{abstract}

Key words: Chaperone, Heat shock proteins, RNA-binding proteins, Heat tolerance, High temperature

CONTACT: Mohammad Pessarakli, professor pessarak@email.arizona.edu School of Plant Sciences, College of Agriculture \& Life Sciences, The University of Arizona, Tucson, Arizona 85721, USA. 


\section{Introduction}

Heat stress caused by increasing global-mean temperature estimated by 1.5 to $2^{\circ} \mathrm{C}$ increase in 2100 (Sorokin and Mondello 2018; Rogelj et al. 2018) is one of the major abiotic stresses that causes severe plant yield loss, approximately by $10 \%$ per degree Celsius from 1 to $5^{\circ} \mathrm{C}$, which occurs even in heat-tolerant plants like sorghum (Tack, Lingenfelser, and Jagadish 2017). Stimulated by heat stress, heat shock proteins (HSPs) and chaperones are found in most prokaryotes and eukaryotes, and even some viruses (Maaroufi and Tanguay 2013; Jacob, Hirt, and Bendahmane 2017; Gomez-Pastor, Burchfiel, and Thiele 2017) and are implicated in regulating diverse signaling pathways, as well as cellular protein quality control and homeostasis. They play critical roles in protein folding, assembly, translocation and degradation in many normal cellular processes, proteins and membranes stabilization, and can assist in protein refolding under stress conditions. Therefore, HSP/chaperones protect plants against various stresses by re-establishing normal protein conformation and cellular homeostasis under normal and stressful conditions (Wang et al. 2004; Gonçalves et al. 2011; Sakurai and Ota 2011; Jacob, Hirt, and Bendahmane 2017). Regulation of these HSPs, RNAbinding proteins (RBPs), and molecular chaperones can be used in plants in order to improve tolerance to heat stress (Balsiger et al. 2004; Kant et al. 2007; Asadi Rahmani et al. 2009; Alexandre and Oliveira 2011; Ji et al. 2017; Zwirowski et al. 2017), the molecular and physiological mechanisms of which have been discussed in this review article to provide more insights into improving plant responses to heat stress.

\section{Roles of HSPs in conferring heat tolerance}

Heat shock proteins are classified into five major families based on their kilodalton (kDa) molecular weight and two groups according to their functions, all of which have high potential to confer tolerance to heat stress. In the first group, "foldases group", HSP70 
(DnaK/Ssa), HSP60 (GroEL or chaperonins), HSP90 (HtpG), and HSP100 (ClpA/B/C; casein lytic proteinase) families are ATP-dependent molecular chaperones involved in folding nascent polypeptides and refolding or correct folding of the heat stress-induced misfolded or unfolded proteins. The second group, ATP-independent 'holdases' include small HSP (sHSP) chaperone family, comprised of a low subunit molecular mass of $12-43 \mathrm{kDa}$, are sequester unfolded or partially folded proteins, which are subsequently processed by the foldases. The sHSP chaperones bind to the non-native substrate proteins and destabilize misfolded conformations and their intermediates, thereby preventing or reversing protein aggregations under heat stress conditions (Koyasu et al. 1989; Wang et al. 2004; Sharma et al. 2013; Kapoor and Roy 2015; Zhang et al. 2015a). The sHSPs interact with HSP40, HSP70, HSP100, and misfolded substrate proteins to facilitate protein solubilization, disaggregation, refolding and, consequently, protein availability and homeostasis, improving cell tolerance, viability, and recovery under heat stress conditions (Smykal et al. 2000; Liberek, Lewandowska, and Ziętkiewicz 2008; Laskowska, Matuszewska, and Kuczynska-Wisnik 2010; Sun et al. 2010; Zwirowski et al. 2017). The chaperone 'holdases', though incapable of folding polypeptides per se, imparts a vital force in prevention of aggregation by binding to unfolded or misfolded conformations to maintain their solubility that are subsequently delivered to the 'foldase' complexes (Kapoor and Roy 2015; Çetinbaş and Shakhnovich, 2015). The HSP90 assists in the maturation of a limited set of substrate proteins that are collectively referred to as client proteins (Wayne, Mishra, and Bolon 2011). Client proteins would then be released for refolding with the help of other ATP-dependent chaperones when the conditions become optimal (Zhang et al. 2015a). The sHSPs have been observed to exist as large homo-oligomers and the reversible dissociation of their oligomers have been reported to be important for their enhanced chaperone activity at high temperatures. Such oligomeric dissociation presumably increases the exposure of their hydrophobic regions, which are 
buried in the oligomers at the normal physiological conditions, but needed for binding nonnative substrate proteins (Zhang et al. 2015a). The proper chaperone function and stress (including, heat stress) management require balance between intracellular levels of holdases, foldases, and client proteins with particular structural (molecular weight and sequences) and functional attributes, though some sHSP might be able to perform a dual function as both holdases and foldases (Li, Soroka, and Buchner 2012; Saibil 2013; Zhang et al. 2015a; Kapoor and Roy 2015; Sekhar et al. 2016). In addition, phosphorylation, acetylation, and other post-translational modifications may regulate chaperone machinery and affect their functions (Khan et al. 1998; Wang et al. 2012; Saibil, 2013; Cloutier and Coulombe 2013; Nitika and Truman 2017). Molecular HSPs/chaperones are located in both the cytoplasm and organelles, such as, nucleus, mitochondria, chloroplasts, symbiosome, endoplasmic reticulum (ER) (Panter et al. 2000; Wang et al. 2004; Reddy et al. 2016), and peroxisome (Ma et al. 2006).

Different classes of molecular chaperones appear to bind to specific non-native substrates to determine their conformational states. Chaperone proteins do not covalently bind to their targets and do not form part of the final product (Wang et al. 2004). Chaperonins, including HSP60 (chaperone (Cpn) 60 or GroEL), HSP10 (Cpn10 or GroES) and TCP-1 (The Chaperonin Containing t-complex polypeptide 1) are ATP dependent chaperones involved in protein translocation (e.g., between endosymbiotic bacteroides into peribacteroid space), protection against denaturation, correct folding, refolding and subsequent assembly and stabilization of some proteins under heat stress conditions (Viitanen et al. 1990; Walters et al. 2002).

\section{Roles of RBPs in conferring heat tolerance}

Proteins that bind to DNA or RNA termed as DNA- and RNA-binding proteins (DRBPs) play critical regulatory roles in cellular processes, including transcription, 
translation, gene silencing, microRNA (miRNA) biogenesis and telomere maintenance (Hudson and Ortlund 2014). RBPs are characterized by the presence of several conserved motifs and domains, including the RNA-recognition motif (RRM), glycine rich (GR) domain, K homology (KH) domain, RGG-box (Arg-Gly-Gly repeats), and zinc-finger motif (Kim et al. 2010). RBPs function as the key post-transcriptional modulators of gene expression and, also, post-translational modifiers of proteins to control a wide range of cellular processes under normal and heat stress conditions. RBPs bind to different types of RNAs encoding the components of the mitogen-activated protein kinases (MAPK) and negatively regulate MAPK signaling by stabilizing MAPK phosphatase mRNA in the cytosol to regulate gene expression and diverse biological processes, which, in turn, regulate RBPs and their target RNAs (Glisovic et al. 2008; Sugiura et al. 2011; Kang, Park, and Kwak 2013; Brown, Mohanty, and Howe 2015; Tsanov and Daley 2017). RBPs regulatory pathways modify protein processes, for example, by regulating methylation, glycosylation, and phosphorylation of RNA chaperones, RNA processing and metabolism, and through the interaction with precursor miRNA (pre-miRNA) proteins as well as the interaction with chaperone proteins (e.g., HSP70-HSP40, mitochondrial HSP70 (mtHSP70)-HSP10, HSP60mtHSP70, HSP70-client proteins), ubiquitin ligase CHIP (carboxy-terminus of Hsc70 interacting protein) and other proteins to confer tolerance to heat stress (Nawrot et al. 2013; He et al. 2008; Glisovic et al. 2008; Rajan and D’Silva 2009; Schlecht et al. 2011; Lee 2012; Kang, Park, and Kwak 2013; Bottinger et al. 2015; Zhang et al. 2015b; Kao et al. 2015; Alves and Goldenberg 2016; Treiber et al. 2017).

Among the plant RBPs, glycine-rich RNA-binding proteins (GR-RBPs), and RNA helicases (RHs) have been determined to function as RNA chaperones under multiple abiotic stresses and chiefly heat stress conditions. However, unlike RBPs that often remain bound to diverse types of RNA molecules to preserve their structures and functions, RNA chaperones 
are no longer needed once RNA molecules have been folded into their native conformations. RNA chaperones are proteins that bind transiently and non-specifically to RNA to resolve kinetically trapped, misfolded conformers by disrupting RNA-RNA interactions and by the loosening of RNA structures, thereby conferring tolerance to heat stress (Rajkowitsch et al. 2007; Castiglioni et al. 2008; Kang, Park, and Kwak 2013; Marchese et al. 2016).

Consequently, RBPs promote tolerance to heat stress by regulating cellular processes via protein-RNA interactions and RNA chaperone activities (Castiglioni et al. 2008; Kang, Park, and Kwak 2013; Marchese et al. 2016). Like RBPs, RNA chaperones confer tolerance to heat stress; however, by regulating gene expression at transcription, post-transcription and posttranslation levels (Arluison et al. 2007; Cloutier and Coulombe 2013). Therefore, coregulation of RBPs together with RNA chaperones might have high potential for improving plant cellular processes and resistance to heat stress, the molecular and physiological processes of which that are required to be investigated.

\section{Glycine-rich RNA-binding proteins (GR-RBPs) roles in heat stress}

GR-RBPs are highly conserved family of proteins involved in post-transcriptional regulation of gene expression, thereby regulating seed germination, growth, development (Kim, Kim, and Kang 2005), DNA- and RNA-melting abilities (Kim et al. 2010), preventing the formation of secondary structures in mRNAs (Lee et al. 2009a) and aiding mRNA export from nucleus to cytoplasm, thereby relating responses to various stresses such as heat stress (Kim et al. 2010). For example, OsGR-RBP4 in rice (Sahi et al. 2007) and RCF3, a KH domain-containing nuclear-localized putative RNA-binding protein in Arabidopsis (Guan et al. 2013) are involved in regulating tolerance to heat stress. 


\section{RNA helicases chaperones (RHs) roles in heat stress}

Helicases are enzymes involved in almost all aspects of RNA and DNA metabolism and gene regulation and, thus, play critical roles in improving plant growth, development, and responses to various stresses such as heat stress (Fairman-Williams, Guenther, and Jankowsky 2010; Huang et al. 2016; Liu, Tabata, and Imai 2016; Shivakumara et al. 2017). Helicases are grouped into four super families based on their amino acid sequences and functions: helicase superfamily (SF) 1 and SF2 are prevalent, while SF3 and SF4 have been reported in viruses (Fairman-Williams, Guenther, and Jankowsky 2010). The RNA helicases (RHs) are a diverse group of RNA-dependent ATPases that contribute to numerous RNA metabolic processes, such as, ribosomal RNA (rRNA) biogenesis, RNA stability, sensing dsRNA and cytoplasmic DNA, RNA unwinding, pre-mRNA splicing, RNA remodeling, export, translation, and degradation, miRNA expression and, thus, are involved in all aspects of RNA metabolism (Jarmoskaite and Russell 2011; König et al. 2013; Zhang et al. 2011; Zhang et al. 2015c; Huang et al. 2016). Most RHs belong to the SF2, characterized by ATPdependent translocation on the nucleic acid substrate and/or induction of RNA conformational changes and further sub-grouped as DEAD-, DEAH- and DExH-box helicases (Jarmoskaite and Russell 2011; König et al. 2013). Many DEAD-box RHs are often multifunctional ATPase proteins involved in diverse RNA metabolism, ranging from RNA synthesis to RNA degradation. DEAD-box RHs use the energy from ATP hydrolysis to unwind short duplex RNA in an unusual process that involves little or no translocation and remodel RNA-protein complexes, but they can also function as RNA clamps to provide nucleation centers that establish larger RNA-protein complexes or even form tight compaction of ssRNA. This activity, coupled with mechanisms to direct different DEADbox proteins to their physiological substrates, allows them to promote RNA folding steps and rearrangements, and to accelerate remodeling of RNA-protein or protein-protein complexes 
in ATP-dependent or ATP-independent reactions, the physiological properties of which that are essential for regulation of responses to heat stress (Linder and Jankowsky 2011; Zhao and Jain 2011; Jarmoskaite and Russell 2011; Kang, Park, and Kwak 2013). The DEAD box RHs regulate the expression of stress-responsive transcriptional activators and function in the ABA-dependent and ABA-independent manners, targeting different genes depending on the stress conditions (Kant et al. 2007). The STRESS RESPONSE SUPPRESSOR1 (STRS1; At1g31970) and STRS2 (At5g08620) genes encode proteins that are members of the large family of approximately 50 Arabidopsis DEAD-box RHs, acting as the negative regulators of the stress responsive genes by the RNA-directed DNA methylation-mediated epigenetic silencing of gene expression under various abiotic stresses stress conditions such as heat stress (Kant et al. 2007; Barak, Singh Yadav, and Khan 2014). Subversion of STRS1 and STRS 2 genes by means of T-DNA insertion enhanced the tolerance of strs mutant seedlings to salt and osmotic stresses and basal and acquired heat stresses in ABA-dependent and ABA-independent manners (Kant et al. 2007). Studies on the DEAD-box RHs demonstrated that the C-terminal domain is important in nonspecific binding of the RNA chaperones to large RNA substrates, while the intrinsically disordered flexible region of the Hfq (host factor Q $\beta$ RNA phage) and virus-encoded RNA chaperones are important for the RNA chaperone activity to confer tolerance to heat stress (Kang, Park, and Kwak 2013).

Wang et al.'s (2016) experiment showed that TOGR1 (Thermotolerant Growth Required1) RH expression effectively improved RNA metabolism, rRNA homeostasis, and rice growth under hot temperatures/heat stress (Wang et al. 2016). In addition to chaperone activities, the RHs such as DEAD helicase are involved in mRNA translation and stabilization under low temperatures and small RNA (sRNA)-mRNA duplex degradation, which is under the influence of Hfq interaction with RNase E and, therefore, affect growth, development and tolerance extreme temperatures (Owttrim 2013). Besides the interactions 
between positive and negative regulators, the expression patterns of stress responsive genes encoding metabolic reprogramming regulating stress responses transiently can be affected by circadian rhythms and different stress conditions due to differential interaction responses of sub-regulatory networks of different stresses, including heat stress (Kant et al. 2007).

Overall, RHs can be used as promising tool for improving plant tolerance to multiple stresses, including heat stress accompanied by optimized productivity (Wang et al. 2016). Since the functions of nucleic binding proteins such as RHs depend on their interactions (Huang et al. 2016; Liu, Tabata, and Imai 2016) and binding properties (Kim et al. 2008), understanding their signaling and regulatory networks, sequences, binding properties and co-expression effects related to their gene expression and metabolic reprogramming will provide further insights into developing tolerant crops with improved performance under both normal and heat stress conditions.

\section{Other molecular chaperones roles in heat stress}

Eukaryotic ribosomes are composed of ribosomal ribonucleic acids (rRNAs) and ribosomal proteins (r-proteins). The rRNA and r-proteins play fundamental roles in cellular processes (i.e., growth, development, and stress responses), acting as both proteins and RNA chaperones (Ting et al. 2016; Ji et al. 2017). The r-proteins are translated in the cytoplasm and imported into the nucleus for assembly with the rRNAs and interact with RNA, DNA, or in some conditions with other proteins to regulate cellular processes (Kovacs et al. 2009). Recently, Ji and co-workers showed that overexpression of r-proteins can be used as an effective tool to improve both plant performance and tolerance to extreme temperatures (Ji et al. 2017). They showed that Sweetpotato (Ipomoea batatas [L.] Lam) overexpressing Arabidopsis ribosomal P3 (AtP3B) gene had greater antioxidant 
activity, photosynthesis and tolerance to both heat and cold temperatures and, consequently, improved yield and storage ability under stress conditions (Ji et al. 2017).

Thioredoxin (TRX) (Lee, Kim, and Lee 2013; Zhu et al. 2014), TRX-like protein (TDX) (Lee et al. 2009b), NADPH-TRX reductase (Chae et al. 2013), glucose regulated protein (GRP94), peptidyl-prolyl isomerases (PPI) or immunophilins (Gupta and Tuteja 2011), histone chaperons (Weng et al. 2014; Tripathi, Pareek, and Singla-Pareek 2016), PDI (Gupta and Tuteja 2011; Zhu et al. 2014), molecular chaperones binding proteins, such as, BiPHSP70, calnexin, and calreticulin proteins (Wang et al. 2004; Carvalho et al. 2014; Ma et al. 2016) are molecular chaperones that participate in cellular processes, such as, growth, development, regulation of responses to various stresses such as heat stress. In this context, regulation of their transcript, for example, by NADPH-TRX reductase-type C overexpression, can be regarded as a promising tool to improve plants symbiosis, growth, development, yield, and tolerance to heat stress (Lee et al. 2005a; Alkhalfioui et al. 2008; Chae et al. 2013). Histone chaperones regulate the expression of genes at transcription levels, regulating protein homeostasis and, thereby, promoting tolerance to multiple stresses, including heat stress. Regulation of histone chaperones has the potential to promote plant stress responses by regulating heritable and non-heritable chromatin and epigenetic based stress memory. Histone chaperons are grouped into seven major families, including CAF1 (Chromatin assembly factor I), FACT (Facilitates chromatin transcription), ASF1 (Antisilencing factor 1), HIRA (Histone regulatory homolog A), NASP (Nuclear Autoantigenic Sperm Protein), SPT6 (Suppressor of Ty element 6), and NAP (Nucleosome Assembly Protein) (Weng et al. 2014; Tripathi, Pareek, and Singla-Pareek 2016). However, the knowledge about the structural, functional diversity, and regulatory roles of theses RNA chaperones and also their implication on symbiosis would provide valuable information for improving plant responses to heat stress in future. 


\section{Concluding remarks}

Since coregulation of the heat shock proteins (HSPs), RNA-binding proteins (RBPs), molecular chaperones, Glycine-rich RNA-binding proteins (GR-RBPs), RNA helicases chaperones (RHs), and other molecular chaperones and their mutual effectiveness under successful symbiotic relationships under both normal and stressful conditions (i.e., heat stress) have not been adequately studied, this review article has provided up-to-date information on this subject. Due to the importance of the effects of these proteins in thermotolerance, it is strongly suggested to evaluate these approaches in breeding programs for heat tolerance in future.

\section{References}

Alexandre, A., S. Oliveira. 2011. Most heat-tolerant rhizobia show high induction of major chaperone genes upon stress. FEMS Microbiology Ecology 75 (1):28-36 doi:10.1111/j.1574-6941.2010.00993.x

Alkhalfioui, F., M. Renard, P. Frendo, C. Keichinger, Y. Meyer, E. Gelhaye, M. Hirasawa, D. B. Knaff, C. Ritzenthaler, C., F. Montrichard. 2008. A novel type of thioredoxin dedicated to symbiosis in legumes. Plant Physiology 148 (1):424-435 doi: $10.1104 / p p .108 .123778$

Alves, L. R., S. Goldenberg. 2016. RNA-binding proteins related to stress response and differentiation in protozoa. World Journal of Biological Chemistry 7 (1):78-87 doi: $\underline{10.4331 / w j b c . v 7 . i 1.78}$

Arluison, V., S. Hohng, R. Roy, O. Pellegrini, P. Régnier, T. Ha. 2007. Spectroscopic observation of RNA chaperone activities of $\mathrm{Hfq}$ in post-transcriptional regulation by a small non-coding RNA. Nucleic Acids Research 35 (3):999-1006 doi:10.1093/nar/gk11124 
Balsiger, S., C. Ragaz, C. Baron, F. Narberhaus. 2004. Replicon-specific regulation of small heat shock genes in Agrobacterium tumefaciens. Journal of Bacteriology 186 (20):6824-6829 doi:10.1128/jb.186.20.6824-6829.2004

Barak, S., N. Singh Yadav, A. Khan. 2014. DEAD-box RNA helicases and epigenetic control of abiotic stress-responsive gene expression. Plant Signaling \& Behavior 9 (12):e977729 doi:10.4161/15592324.2014.977729

Bottinger, L., S. Oeljeklaus, B. Guiard, S. Rospert, B. Warscheid, T. Becker. 2015. Mitochondrial heat shock protein (Hsp) 70 and Hsp10 cooperate in the formation of Hsp60 complexes. The Journal of Biological Chemistry 290:11611-11622 doi: $\underline{10.1074 / \mathrm{jbc} . \mathrm{M} 115.642017}$

Brown, A. S., B. K. Mohanty, P. H. Howe. 2015. Computational identification of post translational modification regulated RNA binding protein motifs. PLOS ONE 10 (9):e0137696 doi:10.1371/journal.pone.0137696

Carvalho, H. H., O. J. B. Brustolini, M. R. Pimenta, G. C. Mendes, B. C. Gouveia, P. A. Silva, J. C. F. Silva, C. S. Mota, J. R. L. Soares-Ramos, E. P. B. Fontes. 2014. The molecular chaperone binding protein bip prevents leaf dehydration-induced cellular homeostasis disruption. PLOS ONE 9 (1):e86661 doi:10.1371/journal.pone.0086661

Castiglioni, P., D. Warner, R. J. Bensen, D. C. Anstrom, J. Harrison, M. Stoecker, M. Abad, G. Kumar, S. Salvador, R. D'Ordine, S. Navarro, S. Back, M. Fernandes, J. Targolli, S. Dasgupta, C. Bonin, M. H. Luethy, J. E. Heard. 2008. Bacterial RNA chaperones confer abiotic stress tolerance in plants and improved grain yield in maize under water-limited conditions. Plant Physiology 147 (2):446-455 doi: $10.1104 / p p .108 .118828$ 
Çetinbaş, M., E. I. Shakhnovich. 2015. Is catalytic activity of chaperones a selectable trait for the emergence of heat shock response? Biophysical Journal 108 (2):438-448 doi:10.1016/j.bpj.2014.11.3468

Chae, H. B., J. C. Moon, M. R. Shin, Y. H. Chi, Y. J. Jung, S. Y. Lee, G. M. Nawkar, H. S. Jung, J. K. Hyun, W. Y. Kim, C. H. Kang, D.-J. Yun, K. O. Lee, S. Y. Lee. 2013. Thioredoxin reductase type c (NTRC) orchestrates enhanced thermotolerance to Arabidopsis by its redox-dependent holdase chaperone function. Molecular Plant 6 (2):323-336 doi: $10.1093 / \mathrm{mp} / \mathrm{sss} 105$

Cloutier, P., Coulombe B. 2013. Regulation of molecular chaperones through posttranslational modifications: Decrypting the chaperone code. Biochimica et Biophysica Acta Gene Regulatory Mechanisms 1829 (5):443-454 doi: $\underline{10.1016 / \mathrm{j} . \text { bbagrm.2013.02.010 }}$

Fairman-Williams, M. E., U. P. Guenther, E. Jankowsky. 2010. SF1 and SF2 helicases: family matters. Current Opinion in Structural Biology 20 (3):313-324 doi:10.1016/j.sbi.2010.03.011

Glisovic, T., J. L. Bachorik, J. Yong, G. Dreyfuss. 2008. RNA-binding proteins and posttranscriptional gene regulation. FEBS letter 582 (14):1977-1986 doi:10.1016/j.febslet.2008.03.004

Gomez-Pastor, R., E. T. Burchfiel, D. J. Thiele. 2017. Regulation of heat shock transcription factors and their roles in physiology and disease. Nature Reviews Molecular Cell Biology 19 (1):4-9. doi:10.1038/nrm.2017.73

Gonçalves, D., J. Lepikson-Neto, M. Salazar, L. Nascimento, E. Camargo, W. Marques, G. Pereira, C. Ramos. 2011. Eucalyptustranscriptome analysis revealed molecular chaperones highly expressed in xylem. BMC Proceedings 5 (7):P109 doi: $\underline{10.1186 / 1753-6561-5-s 7-p 109}$ 
Guan, Q., C. Wen, H. Zeng, J. Zhu. 2013. A KH domain-containing putative RNA-binding protein is critical for heat stress-responsive gene regulation and thermotolerance in Arabidopsis. Molecular Plant 6(2), 386-395. doi:10.1093/mp/sss119

Gupta, D., Tuteja, N. 2011. Chaperones and foldases in endoplasmic reticulum stress signaling in plants. Plant Signaling \& Behavior 6 (2):232-236 doi: $\underline{10.4161 / p s b \cdot 6.2 .15490}$

He, Z., R. Xie, Y. Wang, H. Zou, J. Zhu, G. Yu. 2008. Cloning and characterization of a heat shock protein 70 gene, MsHSP70-1, in Medicago sativa. Acta Biochimica et Biophysica Sinica 40 (3):209-216 doi:10.1111/j.1745-7270.2008.00394.x

Huang, C.K., Y. L. Shen, L. F. Huang, S. J. Wu, C. H. Yeh, C. A. Lu. 2016. The DEAD-Box RNA helicase AtRH7/PRH75 participates in Pre-rRNA processing, plant development and cold tolerance in Arabidopsis. Plant Cell Physiology 57 (1):174-191 doi: $\underline{10.1093 / p c p / p c v 188}$

Hudson, W. H., E. A. Ortlund. 2014. The structure, function and evolution of proteins that bind DNA and RNA. Nature Reviews Molecular Cell Biology 15 (11):749-760 doi: $\underline{10.1038 / \mathrm{nrm} 3884}$

Jacob, P., H. Hirt, A. Bendahmane. 2017. The heat-shock protein/chaperone network and multiple stress resistance. Plant Biotechnology Journal 15 (4):405-414 doi: $10.1111 /$ pbi.12659

Jarmoskaite, I., R. Russell. 2011. DEAD-box proteins as RNA helicases and chaperones. Wiley Interdisciplinary Reviews: RNA 2 (1):135-152 doi:10.1002/wrna.50

Ji, C. Y., R. Jin, Z. Xu, H. S. Kim, C.-J. Lee, L. Kang, S.-E. Kim, H.-U. Lee, J. S. Lee, C. H. Kang, Y. H. Chi, S. Y. Lee, Y. Xie, H. Li, D. Ma, and S.-S. Kwak. 2017. Overexpression of Arabidopsis P3B increases heat and low temperature stress 
tolerance in transgenic sweetpotato. BMC Plant Biology 17 (1):139 doi: $\underline{10.1186 / \mathrm{s} 12870-017-1087-2}$

Kang, H., S. J. Park, K. J. Kwak. 2013. Plant RNA chaperones in stress response. Trends in Plant Science 18 (2):100-106 doi:10.1016/j.tplants.2012.08.004

Kant, P. S. Kant, M. Gordon, R. Shaked, S. Barak. 2007. STRESS RESPONSE SUPPRESSOR1 and STRESS RESPONSE SUPPRESSOR2, two DEAD-box RNA helicases that attenuate Arabidopsis responses to multiple abiotic stresses. Plant Physiology 145 (3):814-830 doi:10.1104/pp.107.099895

Kao, T. Y., Y. C. Chiu, W. C. Fang, C. W. Cheng, C. Y. Kuo, H. F. Juan, S. H. Wu, A. Y. L. Lee. 2015. Mitochondrial Lon regulates apoptosis through the association with Hsp60-mtHsp70 complex. Cell Death and Disease 6:e1642 doi:10.1038/cddis.2015.9

Kapoor, M., Roy, S. S. 2015. Chapter 1: Heat-Shock Proteins and Molecular Chaperones: Role in Regulation of Cellular Proteostasis and Stress Management. In Abiotic Stresses in Crop Plants. Wallingford, UK: CABI. doi:10.1079/9781780643731.0001

Khan, I. U., R. Wallin, R. S. Gupta, G. M. Kammer. 1998. Protein kinase A-catalyzed phosphorylation of heat shock protein 60 chaperone regulates its attachment to histone $2 \mathrm{~B}$ in the $\mathrm{T}$ lymphocyte plasma membrane. Proceedings of the National Academy of Sciences USA 95 (18):10425-10430 doi:10.1073/pnas.95.18.10425

Kim, J. S., K. A. Kim, T. R. Oh, C. M. Park, H. Kang. 2008. Functional characterization of DEAD-box RNA helicases in Arabidopsis thaliana under abiotic stress conditions. Plant Cell Physiology 49 (10):1563-1571 doi:10.1093/pcp/pcn125

Kim, J. Y., W. Y. Kim, K. J. Kwak, S. H. Oh, Y. S. Han, H. Kang. 2010. Glycine-rich RNAbinding proteins are functionally conserved in Arabidopsis thaliana and Oryza sativa during cold adaptation process. Journal of Experimental Botany 61 (9):2317-2325 doi: $10.1093 / \mathrm{jxb} / \mathrm{erq} 058$ 
Kim, Y-O, J. S. Kim, H. Kang. 2005. Cold-inducible zinc finger-containing glycine-rich RNA-binding protein contributes to the enhancement of freezing tolerance in Arabidopsis thaliana. The Plant Journal 42 (6):890-900 doi:10.1111/j.1365$\underline{313 X .2005 .02420 . \mathrm{X}}$

König, S. L. B., P. S. Liyanage, R. K. O. Sigel, D. Rueda. 2013. Helicase-mediated changes in RNA structure at the single-molecule level. RNA Biology 10 (1):133-148 doi: $10.4161 /$ rna.23507

Kovacs, D., M. Rakacs, B. Agoston, K. Lenkey, K. Semrad, R. Schroeder, P. Tompa. 2009. Janus chaperones: Assistance of both RNA- and protein-folding by ribosomal proteins. FEBS letter 583 (1):88-92 doi:10.1016/j.febslet.2008.11.049

Koyasu, S., E. Nishida, Y. Miyata, H. Sakai, I. Yahara. 1989. HSP100, a 100-kDa heat shock protein, is a $\mathrm{Ca}^{2+}$-calmodulin-regulated actin-binding protein. Journal of Biological Chemistry 264 (25):15083-15087

Laskowska, E., E. Matuszewska, D. Kuczynska-Wisnik. 2010. Small heat shock proteins and protein-misfolding diseases. Current Pharmaceutical Biotechnology 11 (2):146-157 doi: $\underline{10.2174 / 138920110790909669}$

Lee, E. K. 2012. Post-translational modifications of RNA-binding proteins and their roles in RNA granules. Current Protein \& Peptide Science 13 (4):331-336 doi: $10.2174 / 138920312801619411$

Lee, M.-O., K. P. Kim, B.-g. Kim, J.-S. Hahn, C.B. Hong. 2009a. Flooding stress-induced glycine-rich RNA-binding protein from Nicotiana tabacum. Molecules and Cells 27 (1):47-54 doi:10.1007/s10059-009-0004-4

Lee, J. R., S. S. Lee, H. H. Jang, Y. M. Lee, J. H. Park, S.-C. Park, J. C. Moon, S. K. Park, S. Y. Kim, S. Y. Lee, H. B. Chae, Y. J. Jung, W. Y. Kim, M. R. Shin, G.-W. Cheong, M. G. Kim, K. R. Kang, K. O. Lee, D.-J. Yun, S. Y. Lee. 2009b. Heat-shock dependent 
oligomeric status alters the function of a plant-specific thioredoxin-like protein, AtTDX. Proceedings of the National Academy of Sciences USA 106 (14):5978-5983 doi: $10.1073 /$ pnas.0811231106

Lee, S., S. M. Kim, R. T. Lee. 2013. Thioredoxin and thioredoxin target proteins: from molecular mechanisms to functional significance. Antioxidants \& Redox Signaling 18 (10):1165-1207 doi:10.1089/ars.2011.4322

Li, J., J. Soroka, J. Buchner. 2012. The Hsp90 chaperone machinery: Conformational dynamics and regulation by co-chaperones. Biochimica et Biophysica Acta (BBA) - Molecular Cell Research 1823:624-635 doi:10.1016/j.bbamcr.2011.09.003

Liberek, K., A. Lewandowska, S. Ziętkiewicz. 2008. Chaperones in control of protein disaggregation. The EMBO Journal 27:328-335 doi:10.1038/sj.emboj.7601970

Linder, P., E. Jankowsky. 2011. From unwinding to clamping — the DEAD box RNA helicase family. Nature Reviews Molecular Cell Biology 12 (8):505-516 doi: $\underline{10.1038 / \mathrm{nrm} 3154}$

Liu, Y., D. Tabata, R. Imai. 2016. A cold-inducible DEAD-Box RNA helicase from Arabidopsis thaliana regulates plant growth and development under low temperature. PLOS ONE 11 (4):e0154040 doi:10.1371/journal.pone.0154040

Ma, C., M. Haslbeck, L. Babujee, O. Jahn, S. Reumann. 2006. Identification and characterization of a stress-inducible and a constitutive small heat-shock protein targeted to the matrix of plant peroxisomes. Plant Physiology 141 (1):47-60 doi: $\underline{10.1104 / p p .105 .073841}$

Maaroufi, H., R. M. Tanguay. 2013. Analysis and phylogeny of small heat shock proteins from marine viruses and their cyanobacteria host. PLOS ONE 8 (11):e81207 doi: $\underline{10.1371 / \text { journal.pone. } 0081207}$ 
Marchese, D., N. S. de Groot, N. Lorenzo Gotor, C. M. Livi, G. G. Tartaglia. 2016. Advances in the characterization of RNA-binding proteins. Wiley Interdisciplinary Reviews: RNA 7:793-810 doi:10.1002/wrna.1378

Nawrot, R., L. Tomaszewski, A. Czerwoniec, A. Gozdzicka-Jozefiak. 2013. Identification of a coding sequence and structure modeling of a glycine-rich RNA-binding protein (CmGRP1) from Chelidonium majus L. Plant Molecular Biology Reporter 31 (2):470-476 doi:10.1007/s11105-012-0510-y

Nitika, A. W. T. 2017. Cracking the chaperone code: cellular roles for Hsp70 phosphorylation. Trends in Biochemical Sciences 42 (12):932-935 doi: $10.1016 /$ j.tibs.2017.10.002

Owttrim, G. W. 2013. RNA helicases: Diverse roles in prokaryotic response to abiotic stress. RNA Biology 10 (1):96-110 doi: $\underline{10.4161 / \text { rna.22638 }}$

Panter, S., R. T homson, G. de Bruxelles, D. Laver, B. Trevaskis, M. Udvardi. 2000. Identification with proteomics of novel proteins associated with the peribacteroid membrane of soybean root nodules. Molecular Plant-Microbe Interactions 13 (3):325-333 doi:10.1094/MPMI.2000.13.3.325

Rajan, V. B. V., P. D’Silva. 2009. Arabidopsis thaliana J-class heat shock proteins: cellular stress sensors. Functional \& Integrative Genomics 9 (4):433 doi:10.1007/s10142-009$\underline{0132-0}$

Rajkowitsch, L., D. Chen, S. Stampfl, K. Semrad, C. Waldsich, O. Mayer, M. F. Jantsch, R. Konrat, U. Bläsi, R. Schroederet. 2007. RNA chaperones, RNA annealers and RNA helicases. RNA Biology 4 (3):118-130 doi: $\underline{10.4161 / \text { rna.4.3.5445 }}$

Reddy, P. S., T. Chakradhar, R. A. Reddy, R. B. Nitnavare, S. Mahanty, M. K. Reddy. 2016. Role of Heat Shock Proteins in Improving Heat Stress Tolerance in Crop Plants. In: Asea A. A. A., P. Kaur, S. K. Calderwood (eds) Heat Shock Proteins and Plants. Vol. 
10. Springer International Publishing, Cham, pp 283-307. doi:10.1007/978-3-319$\underline{46340-7 \quad 14}$

Rogelj, J., A. Popp, K. V. Calvin, G. Luderer, J. Emmerling, D. Gernaat, S. Fujimori, J. Strefler, T. Hasegawa, G. Marangoni, V. Krey, E. Kriegler, K. Riahi, D. P. van Vuuren, J. Doelman, L. Drouet, J. Edmonds, O. Fricko, M. Harmsen, P. Havlík, F. Humpenöder, E. Stehfest, M. Tavoni. 2018. Scenarios towards limiting global mean temperature increase below $1.5^{\circ} \mathrm{C}$. Nature Climate Change 8 (4):325-332. doi: $\underline{10.1038 / \mathrm{s} 41558-018-0091-3}$

Sahi, C., M. Agarwal, A. Singh, A. Grover. 2007. Molecular characterization of a novel isoform of rice (Oryza sativa L.) glycine rich-RNA binding protein and evidence for its involvement in high temperature stress response. Plant Science 173 (2):144-155. doi:10.1016/j.plantsci.2007.04.010

Saibil, H. 2013. Chaperone machines for protein folding, unfolding and disaggregation. Nature Reviews Molecular Cell Biology 14 (10):630-642 doi:10.1038/nrm3658

Sakurai, H., A. Ota. 2011. Regulation of chaperone gene expression by heat shock transcription factor in Saccharomyces cerevisiae: Importance in normal cell growth, stress resistance, and longevity. FEBS letter 585 (17):2744-2748 doi:10.1016/j.febslet.2011.07.041

Schlecht, R., A. H. Erbse, B. Bukau, M. P. Mayer. 2011. Mechanics of Hsp70 chaperones enables differential interaction with client proteins. Nature Structural and Molecular Biology 18 (3):345-351 doi:10.1038/nsmb.2006

Sekhar, A., R. Rosenzweig, G. Bouvignies, L. E. Kay. 2016. Hsp70 biases the folding pathways of client proteins. Proceedings of the National Academy of Sciences USA 113 (20):E2794-E2801 doi:10.1073/pnas.1601846113 
Sharma, S., S. Sarkar, S. S. Paul, S. Roy, K. Chattopadhyay. 2013. A small molecule chemical cahaperone optimizes its unfolded state contraction and denaturant like properties. Scientific Report 3 (1):3525 doi:10.1038/srep03525

Shivakumara, T. N., R. Sreevathsa, P. K. Dash, M. S. Sheshshayee, P. K. Papolu, U. Rao, N. Tuteja, M. UdayaKumar. 2017. Overexpression of Pea DNA Helicase 45 (PDH45) imparts tolerance to multiple abiotic stresses in chili (Capsicum annuum L.) Scientific Report 7 (1):2760 doi:10.1038/s41598-017-02589-0

Smykal, P., J. Masin, I. Hrdy, I. Konopasek, V. Zarsky. 2000. Chaperone activity of tobacco HSP18, a small heat-shock protein, is inhibited by ATP. The Plant Journal 23 (6):703-713 doi:10.1046/j.1365-313x.2000.00837.x

Sorokin, L. V., G. Mondello. 2018. Entering the New $+2{ }^{\circ} \mathrm{C}$ Global Warming Age and a Threat of World Ocean Expansion for Sustainable Economic Development, In: Mal, S., R.B. Singh, C. Huggel (eds.), Climate Change, Extreme Events and Disaster Risk Reduction: Towards Sustainable Development Goals. Springer International Publishing, Cham, pp. 183-201. doi:10.1007/978-3-319-56469-2__13

Sugiura, R., R. Satoh, S. Ishiwata, N. Umeda, A. Kita. 2011. Role of RNA-Binding Proteins in MAPK Signal Transduction Pathway. Journal of Signal Transduction 2011(109746):1-8 doi:10.1155/2011/109746

Sun, J.-h., J.-y. Chen, J.-f. Kuang, W.-x. Chen, W.-j. Lu. 2010. Expression of sHSP genes as affected by heat shock and cold acclimation in relation to chilling tolerance in plum fruit. Postharvest Biology and Technology 55 (2):91-96 doi:10.1016/j.postharvbio.2009.09.001

Tack, J., J. Lingenfelser, S. V. K. Jagadish. 2017. Disaggregating sorghum yield reductions under warming scenarios exposes narrow genetic diversity in US breeding programs. 
Proceedings of the National Academy of Sciences 114 (35):9296-9301. doi: $\underline{10.1073 / p n a s .1706383114}$

Ting, Y.-H., T.-J. Lu, A. W. Johnson, J.-T. Shie, B.-R. Chen, S. S., Kumar., K.-Y. Lo. 2016. Bcp1 is the nuclear chaperone of the 60S ribosomal protein Rp123 in Saccharomyces cerevisiae. Journal of Biological Chemistry 292 (2):585-596 doi:10.1074/jbc.M116.747634

Treiber, T., N. Treiber, U. Plessmann, S. Harlander, J.-L. Daiß, N. Eichner, G. Lehmann, K. Schall, H. Urlaub, G. Meister. 2017. A compendium of RNA-binding proteins that regulate MicroRNA. Biogenesis. Molecular Cell 66 (2):270-284.e213 doi:10.1016/j.molcel.2017.03.014

Tripathi, A. K., A. Pareek, S. L. Singla-Pareek. 2016. A NAP-family histone chaperone functions in abiotic stress response and adaptation. Plant Physiology 171 (4):28542868 doi: $\underline{10.1104 / p p .16 .00408}$

Tsanov, K. M., G. Q. Daley. 2017. Signaling through RNA-binding proteins as a cell fate regulatory mechanism. Cell Cycle 16 (8):723-724 doi: $\underline{10.1080 / 15384101.2017 .1302205}$

Viitanen, P. V., T. H. Lubben, J. Reed, P. Goloubinoff, D. P. O'Keefe, G. H. Lorimer. 1990. Chaperonin-facilitated refolding of ribulose bisphosphate carboxylase and ATP hydrolysis by chaperonin 60 (groEL) are potassium dependent. Biochemistry 29 (24):5665-5671 doi:10.1021/bi00476a003

Walters, C., N. Errington, A. J. Rowe, S. E. Harding. 2002. Hydrolysable ATP is a requirement for the correct interaction of molecular chaperonins cpn60 and cpn10. Biochemical Journal 364 (3):849-855 doi:10.1042/BJ20011643 
Wang, D., B. Qin, X. Li, D. Tang, Y. Zhang, Z. Cheng, Y. Xue. 2016. Nucleolar DEAD-box RNA helicase TOGR1 regulates thermotolerant growth as a pre-rRNA chaperone in rice. PLOS Genetics 12 (2):e1005844 doi:10.1371/journal.pgen.1005844

Wang, W., B. Vinocur, O. Shoseyov, A. Altman. 2004. Role of plant heat-shock proteins and molecular chaperones in the abiotic stress response. Trends in Plant Science 9 (5):244-252 doi:10.1016/j.tplants.2004.03.006

Wang, X., X.-a. Lu, X. Song, W. Zhuo, L. Jia, Y. Jiang, Y. Luo. 2012. Thr ${ }^{90}$ phosphorylation of Hsp90 $\alpha$ by protein kinase A regulates its chaperone machinery. Biochemical Journal 441 (1):387-397 doi:10.1042/bj20110855

Wayne, N., P. Mishra, D. N. Bolon. 2011. Hsp90 and Client Protein Maturation. In: Calderwood S., T. Prince (eds) Molecular Chaperones. Methods in Molecular Biology (Methods and Protocols) Vol. 787:33-44 Humana Press. doi:10.1007/978-1-61779$\underline{295-3 \quad 3}$

Zhang K, A. N. Ezemaduka, Z. Wang, H. Hu, X. Shi, C. Liu, X. Lu, X. Fu, Z. Chang, C.-C. Yin. 2015a. A novel mechanism for small heat shock proteins to function as molecular chaperones. Scientific Reports 5 (1):8811 doi:10.1038/srep08811

Zhang, H. J. Amick, R. Chakravarti, S. Santarriaga, S. Schlanger, C. McGlone, M. Dare, J. C. Nix, K. M. Scaglione, D. J. Stuehr, S. Misra, R. C. Page. 2015b. A bipartite interaction between Hsp70 and CHIP regulates ubiquitination of chaperoned client proteins. Structure 23 (3):472-482 doi:10.1016/j.str.2015.01.003

Zhang, Z., T. Kim, M. Bao, V. Facchinetti, S. Y. Jung, A. A. Ghaffari, J. Qin, G. Cheng, Y.J. Liu. 2011. DDX1, DDX21, and DHX36 helicases form a complex with the adaptor molecule TRIF to sense dsRNA in Dendritic. Cells Immunity 34 (6):866-878 doi: $10.1016 /$ j.immuni.2011.03.027 
Zhao, X., C. Jain. 2011. DEAD-box proteins from Escherichia coli exhibit multiple ATPindependent activities. Journal of Bacteriology 193 (9):2236-2241 doi: $10.1128 / \mathrm{jb} .01488-10$

Zhu, C., N. Luo, M. He, G. Chen, J. Zhu, G. Yin, X. Li, Y. Hu, J. Li, Y. Yan. 2014. Molecular characterization and expression profiling of the protein disulfide isomerase gene family in Brachypodium distachyon. L. PLoS ONE 9 (4):e94704 doi: $10.1371 /$ journal.pone.0094704

Zwirowski, S., A. Kłosowska, I. Obuchowski, N. B. Nillegoda, A. Piróg, S. Ziętkiewicz, B. Bukau, A. Mogk, K. Liberek. 2017. Hsp70 displaces small heat shock proteins from aggregates to initiate protein refolding. EMBO Journal 36 (6):783-796 doi:10.15252/embj.201593378 